\title{
Financial Sustainability of an Oregon Rural Health, Primary Care, and Pharmacist-Run Comprehensive Medication Management Program Through Direct Medical Billing
}

\author{
Nathan D. Hoover, PharmD; R. Brigg Turner, PharmD, BCPS-AQ ID; Jaime Sampson; \\ Tiffanie Pye, PharmD, BCPS; and Tanie Hotan, MD
}

\begin{abstract}
BACKGROUND: Although several states recognize pharmacists as providers and allow credentialing, this practice is not recognized nationwide.

Following adoption of Oregon House Bill 2028, pharmacists are recognized as providers, allowing "health insurers to provide payment or reimbursement for their services to patients." Before this law, and in several instances currently, pharmacist-run programs were financially justified through soft dollars saved by improving patient outcomes, reducing emergency department use, and decreasing readmission rates.
\end{abstract}

OBJECTIVE: To determine if direct billing of third-party payers covers the direct cost of a comprehensive medication management (CMM) program in an ambulatory rural health adult population with uncontrolled diabetes or hypertension.

METHODS: This study of a population derived from 2 Oregon rural health primary care clinics was a retrospective chart review of adults (aged $\geq 18$ years) with a primary diagnosis of diabetes mellitus or hypertension who completed a CMM visit with a clinical pharmacist from March 2017 to June 2018. In determining the financial sustainability of a pharmacist-run CMM program, the following primary outcomes were evaluated: (a) percentage of visits completed per insurance type; (b) median reimbursement rate (dollars per visit) per insurance type; and (c) the estimated number of visits per day to cover $100 \%$ of the total CMM cost annually. The secondary outcome was the percentage of the major third-party payers that allowed credentialing of pharmacists. All outcomes were evaluated using descriptive statistics.

RESULTS: 664 CMM visits were included. Visits per insurance type comprised Medicare Advantage (34\%), traditional Medicare (25\%), Oregon State Medicaid (20.9\%), commercial (17.8\%), and self-pay (cash; 1.4\%). Median reimbursement rate (dollars per visit) was highest from Oregon Medicaid, followed by Medicare Advantage, and lowest among commercial, self-pay (cash), and traditional Medicare. Total reimbursement received throughout the duration of this pilot project covered $14.1 \%$ of the total CMM program cost. It was estimated that approximately 17 visits per day are needed to cover $100 \%$ of the total CMM cost annually per pharmacist relying solely on direct revenue within these clinics. Currently, of the 18 contracted insurance companies, only $50 \%$ recognize and allow credentialing of pharmacists as providers.

CONCLUSIONS: Pharmacist-run services within the 2 rural health primary care clinics were not financially justifiable via direct billing of third-party payers alone. The lack of credentialing, recognition of pharmacists as providers, and reimbursement is inadequate for program expansion and sustainability without relying on additional revenue streams or benefits from improved patient outcomes. Currently, federal insurance significantly contributes to this lack of funding.

J Manag Care Spec Pharm. 2020;26(1):30-34

Copyright $\odot 2020$, Academy of Managed Care Pharmacy. All rights reserved.

\section{What is already known about this subject}

Pharmacist-run services have been financially justified through demonstration of improved patient outcomes instead of revenue generated.

Differing federal and state laws with regards to pharmacist-provider status has added confusion to how pharmacists are allowed to bill within an already complex billing process.

\section{What this study adds}

This study demonstrates an imbalance between patient use of pharmacist-run services by insurance type and reimbursement received by third-party payers.

Development and expansion of pharmacist-run programs within resource-limited settings, such as those represented in this study, are threatened by the lack of evidence to financially justify such programs via revenue generated alone.

This study suggests a continual need to advocate for pharmacists to obtain provider status at the federal level and be eligible to bill directly for services rendered to improve patient outcomes.

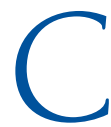
omprehensive medication management (CMM) programs, often synonymous with chronic care management or ambulatory care pharmacist services, are pharmacist-run services that provide direct management of chronic diseases, such as diabetes, hypertension, and hypocholesteremia. The need for ambulatory care pharmacists is ever increasing as is evident by the expansion of these services beyond common chronic disease states to more specific disease states, such as epilepsy, pain management, and rheumatology. ${ }^{1}$

Benefits of these services have been documented and include improved patient outcomes, decreased emergency department (ED) use, and decreased hospital readmission rates. ${ }^{2,3}$ However, owing to differing federal and state laws, credentialing as billable providers is difficult and often beyond the knowledge and expertise of pharmacists. ${ }^{4}$ This often results in pharmacist services being justified by anticipated soft dollars saved through improved patient outcomes instead of through revenue generation via directly billing for services rendered by pharmacists. While this tactic of justification has proved 
effective in some circumstances, the lack of financial sustainability of pharmacist-run services has led to a dearth of such services in resource-limited settings such as stand-alone physician offices, clinics not associated with large health systems or without federal grants, and other rural settings, since stakeholders may rely on hard dollars earned rather than soft dollars saved to justify these services. ${ }^{4}$

In 2015, Oregon House Bill 2028 was signed into law, which recognizes pharmacists as providers and permits "health insurers to provide payment or reimbursement for their services to patients." ${ }^{5,6}$ Although the state of Oregon recognizes pharmacists as billable providers, such billing practices have not been widely adopted. One reason for this may be attributed to the lack of recognition of provider status at the federal level, making billing for pharmacist-rendered services difficult, even in a state that recognizes pharmacists as billable providers. As a result, the objective of this study was to determine if direct billing of third-party payers covers the direct cost of a CMM program in an ambulatory rural health adult population with uncontrolled diabetes or hypertension.

\section{Methods}

\section{Study Design}

This study was a retrospective chart review of patients who completed a CMM visit from March 2017 to June 2018. Patients included in the study were voluntarily referred to the CMM program by their primary care providers within 2 designated primary care clinics. Because this was a pilot program, no special promotion was done during this time to expand the program beyond the 2 designated clinics included in this study. Data collected in this study were deidentified with no possibility of reidentification and stored in a secure manner approved by the Institutional Review Board of Pacific University.

\section{Study Setting}

Santiam Hospital is a 40-bed acute care hospital that also owns and operates 6 primary care and 7 specialty clinics. Santiam Hospital is located in Stayton, OR, while the clinics are located in multiple nearby rural communities, serving a population of over 30,000 people. In 2016, Santiam Hospital, in partnership with a locally owned community pharmacy, Sublimity Pharmacy Services, was awarded a grant from Willamette Valley Community Health, a local provider of Oregon Medicaid, that partially funded a pilot CMM program that employed two 0.5 full-time equivalent clinical pharmacists within 2 of its medical clinics. These outpatient clinical services were only available within Aumsville and Santiam medical clinics. Both are small rural health primary care clinics that are recognized as patient-centered primary care homes.

\section{Inclusion and Exclusion}

Eligible patients for this study included any patient aged 18 years or older with a primary diagnosis of type 2 diabetes mellitus or hypertension who had at least 1 billable CMM visit with a clinical pharmacist between March 2017 and June 2018. Only completed visits were included. Cancelled and missed appointments were not included in the analysis of this study. Patients known to be prisoners, pregnant, or mentally disabled were also excluded.

\section{Clinical Pharmacist Care Delivery}

The initial goal of the CMM pilot program was to reduce polypharmacy, defined as any patient with 5 or more active prescriptions for chronic disease state management. After several months of observation, it was noted that many patients enrolled in this program also had a diagnosis of diabetes and/or hypertension. As a result of this observation and because of the difficulty in tracking polypharmacy endpoints, a natural transition within the CMM program took place to instead recruit patients with a diagnosis of uncontrolled diabetes and hypertension as a goal to also decrease polypharmacy in this population.

\section{Insurance Credentialing and Contracting}

To be recognized as an authorized provider and to ensure that a third-party reimbursement can be requested, providers need to navigate through a 2-step process of insurance credentialing and insurance contracting. The typical credentialing process in the state of Oregon includes filing an Oregon Practitioner Credentialing Application, which includes, but is not limited to, a verification of provider education, residency training, and liability insurance status. In addition, some insurance companies also require the use of an online credentialing tool, such as that of the Council for Affordable Quality Healthcare. This tool acts as a database to store provider information and is used to "streamline the business of healthcare." Once a provider is credentialed, they become eligible to be contracted either individually or via an already existing contract between a health care facility and the third-party payer. Simply put, contracts are "the rules" that a provider/facility agree to in order to ensure that third-party reimbursement can be requested by a provider. At minimum, the credentialing process may take 90-120 days from the time the information is received by the insurance company and an additional 30-60 days for contracting to be completed.

Within the state of Oregon, the credentialing process does not differ greatly when credentialing a pharmacist compared with a medical provider (e.g., physician, physician assistant, and nurse practitioner). Of the several different insurance companies with which Santiam contracts, only a handful recognize a pharmacist as a billable provider (see Table 1). 
Financial Sustainability of an Oregon Rural Health, Primary Care, and Pharmacist-Run

Comprehensive Medication Management Program Through Direct Medical Billing

TABLE 1 Major Third-Party Payer Credentialing and Reimbursement

\begin{tabular}{|c|c|c|c|c|c|c|c|}
\hline Third-Party Insurer & Classification & Credentialed & $\begin{array}{c}\text { Provides } \\
\text { Reimbursement }\end{array}$ & Visits, $\mathrm{n}$ & Net Received, \$ & $\begin{array}{c}\text { Median + (IQR) } \\
\text { Reimbursement } \\
\text { Rate, \$/visit }\end{array}$ & $\begin{array}{c}\% \text { of CMM } \\
\text { Program Paid by } \\
\text { Reimbursement }\end{array}$ \\
\hline Atrio & \multirow{4}{*}{ State Medicaid } & Yes & Yes & \multirow{4}{*}{139} & \multirow{4}{*}{10,746} & \multirow{4}{*}{$(51-80)$} & \multirow{4}{*}{4.7} \\
\hline Care Oregon & & Yes & Yes & & & & \\
\hline DMAP & & Yes & Yes & & & & \\
\hline WVCH & & Yes & Yes & & & & \\
\hline Medicare Part Ba & \multirow{3}{*}{ Federal } & No & $\mathrm{No}^{\mathrm{c}}$ & 166 & 86 & $(0-0)$ & Negligible \\
\hline Medicare Part $\mathrm{C}^{\mathrm{b}}$ & & \multicolumn{2}{|c|}{ See individual insurance companies } & 226 & 12,821 & $36 \quad(0-69)$ & 5.6 \\
\hline Tricare & & No & No & 6 & 199 & $(0-63)$ & Negligible \\
\hline Cigna & \multirow{8}{*}{ Commercial } & No & No & \multirow{8}{*}{118} & \multirow{8}{*}{3,976} & \multirow{8}{*}{$(0-67)$} & \multirow{8}{*}{1.7} \\
\hline First Choice Health & & Yes & Yes & & & & \\
\hline Health Net & & Yes & Yes & & & & \\
\hline Moda & & No & Yes $^{\mathrm{d}}$ & & & & \\
\hline Pacificsource & & Yes & Yes & & & & \\
\hline Providence & & $\mathrm{No}^{\mathrm{e}}$ & No & & & & \\
\hline Regence & & Yes & Yes & & & & \\
\hline United Health Care & & Yes & Yes & & & & \\
\hline Cash & \multirow{2}{*}{ Self-pay } & \multicolumn{2}{|c|}{ Not applicable } & 9 & 173 & $(0-0)$ & Negligibleg \\
\hline Copay & & Not applicable & $\mathrm{O}^{\mathrm{f}}$ & 4,317 & - & 1.9 & \\
\hline $\begin{array}{l}\text { aTraditional Medicare. } \\
{ }^{b} \text { Medicare Advantage. } \\
{ }^{c} \text { Medicare may reimbur } \\
{ }^{d} \text { Moda does not credent } \\
\text { eProvidence may creder } \\
\text { fVisits already accounte } \\
\text { gReimbursement rate } ~ \\
\text { CMM = comprehensive } \\
\text { WVCH = Willamette Va }\end{array}$ & $\begin{array}{l}\text { harmacist at the } \\
\text { harmacist; howev } \\
\text { once specific qual } \\
\text { in above insuran } \\
\text { sit. } \\
\text { cation manageme } \\
\text { Community Healt }\end{array}$ & $\begin{array}{l}\text { M level of } 99211 \text {, } \\
r \text { they do pay clain } \\
\text { ications (e.g., board } \\
\text { categories. } \\
\text { t; DMAP = Division }\end{array}$ & $\begin{array}{l}\text { fined as a "simple pa } \\
\text { ertification, residenc }\end{array}$ & $\begin{array}{l}\text { tencounter } \\
\text { tining) are } n\end{array}$ & valuation and mana & ement; $I Q R=$ interq & artile range; \\
\hline
\end{tabular}

Lack of pharmacist credentialing can be a major barrier to patient care for one of the following reasons: (a) patients may be required to pay out of pocket for services or (b) no reimbursement is received by the clinic for pharmacist-run services. Federal insurers, such as Medicare, and commercial insurers, such as Aetna and Cigna, represent a few examples of the insurers that will not credential a pharmacist as a provider. For pharmacist credentialing, most insurance companies require completion of a PGY-1 residency accredited by the American Society of Health-System Pharmacists and at least one of the following: board certification from the Board of Pharmaceutical Specialties in any discipline, board certified advanced diabetes management (BC-ADM), certified diabetes educator (CDE), or certified geriatric pharmacist (CGP).

\section{Billing of CMM Services}

Third-party payers were billed using category 1 , evaluation and management (E\&M) code 99213 (99211-99215), part of the Current Procedure Terminology codes. E\&M code 99211 refers to a simple patient encounter, while 99215 refers to the most complex patient encounter. ${ }^{8}$ To bill at the level of 99213 (defined as expanded problem-focused encounter), a provider must document a minimum of a 15-minute visit length, a chief complaint, a brief history of present illness, a review of systems, and greater than 6 elements in 1 organ system during a physical examination. ${ }^{9}$

\section{Outcomes}

The objective of this study was to determine if direct billing of third-party payers covered the direct cost of a CMM program in an ambulatory rural health adult population with uncontrolled diabetes or hypertension. Evaluation was based on the following 3 outcomes: (1) percentage of visits completed per insurance type; (2) median reimbursement rate (dollars received per visit) per insurance type; and (3) the estimated number of visits per day needed to cover $100 \%$ of the total CMM cost annually. The secondary outcome was the percentage of the major third-party payers (insurances) that allowed credentialing of pharmacists.

\section{Statistical Analysis}

The primary and secondary outcomes were analyzed using descriptive statistics. Normality of continuous data was assessed visually and by the Shapiro-Wilk test. Nonparametric data are presented as median (interquartile range [IQR]). 


\section{Results}

\section{Primary Outcome}

A total of 664 visits were included in this study, with the majority (81.0\%) composed of government insurance (60\% federal and $\sim 21 \%$ state). The overall payer mix comprised Medicare Advantage, Part C (34\%), traditional Medicare, Part B (25.0\%), Medicaid (20.9\%), commercial (17.8\%), self-pay/cash (1.4\%), and Tricare (0.9\%).

The total cost of this CMM program was $\$ 229,207.38$, with an annual cost estimated at $\$ 145,000$ which was composed mainly of a pharmacist's salary and benefits. Other direct and indirect costs were not reflected in the estimated total cost but still were contributed to by the pharmacist. Examples of these may have included salary of support personnel, equipment, laptops, building cost, and utilities. The total reimbursement received during the length of this pilot project covered $14.1 \%$ of the total CMM program cost (Table 1). With a median reimbursement of $\$ 36$ per visit (IQR $=\$ 10-\$ 76$ ), approximately 17 visits per day were needed at these rural health clinics to cover the annual costs of the program through direct reimbursement only.

\section{Secondary Outcome}

A total of 18 insurance companies were contracted with Santiam Hospital and clinics. Of these, 14 were considered major insurer contracts. Half of the total contracted insurance companies $(50 \%)$ and $64 \%$ of the major contracted insurers credentialed pharmacists as providers and allowed billing. Oregon State Medicaid and commercial payers were the majority of insurance providers that allowed for credentialing and billing, while federal insurers (such as Medicare) did not credential pharmacists nor allowed for direct billing (Table 1).

\section{Discussion}

This study suggests an imbalance between billing and patient load in those patients insured by Medicare Part B and Oregon State Medicaid. Medicare Part B used the greatest resources, yet paid significantly less than Oregon State Medicaid. Since Medicare Part B may not cover all claims, many people opt for additional coverage through Medicare Part C, which is supplemented by a private/commercial insurer. These supplemental insurers may or may not reimburse for pharmacistrendered services, depending on whether they strictly follow federal law or yield to state laws with regards to pharmacist provider and credentialing status. As of November 2019, the challenges of billing and expanding pharmacist-run services, especially within small, rural communities continue and will do so, until federal and state laws agree and recognize pharmacists as billable providers. This difference between federal and state law in recognition of pharmacist as providers further supports a claim by a group of panelists reported by Carrington et al. (2018) "that the billing capability of the pharmacist should not be considered when approaching practices so as not to associate revenue generation with the value added of the pharmacist." 10,11 However, this strategy is in stark contrast to other types of providers (including those not authorized to diagnosis or independently prescribe medication, such as physical and occupational therapists) who are financially sustainable. We suggest that in addition to the positive patient outcomes and contributions resulting from pharmacist-run services, such services should be equally and universally billable at the state and federal levels.

In determining the financial sustainability of pharmacistrun services, 3 primary methods may be used. First, financial justification via soft dollars saved through improved patient outcomes, decrease of unnecessary ED use, and fewer penalties for 30-day patient readmissions. Second, improved patient outcomes are often proportional with an increase in meeting quality metrics. Meeting these metrics, set by various organizations depending on facility type, in addition to recognition in the state of Oregon as a patient-centered primary care home and/ or rural health facility, such as that of Santiam Hospital and clinics, allows for an increased amount of upfront funding that may be used for improved or new patient care services, but not necessarily directly related to pharmacist-run services. Third, and the newest of the 3 methods, is the financial justification via hard dollars earned as revenue via direct reimbursement.

Pharmacists may justify their services by only allowing patients with payable insurers to use these programs; however, this may appear as fraudulent behavior. Also, pharmacists can increase the volume of patients seen per day; however, increasing patient load may threaten the strengths of pharmacist-run services (i.e., pharmacist expertise in medication and the ability to spend up to 30-60 minutes in each visit). A recent study by Fixen et al. (2018) focused specifically on billing Medicare through incident-to billing. ${ }^{12}$ It was found that, at most, if a pharmacist solely focused on chronic care management visits, this program could generate an estimated $\$ 78,431.52$ each year in revenue, well below the cost of such a program. ${ }^{12}$ Another similarity between the Fixen study and our study is that the responsibilities of the pharmacists extended beyond direct patient care, and visits were usually well beyond the $20 \mathrm{~min}$ utes required by Medicare for incident-to billing. ${ }^{13}$ As this is the case, it would be impossible for pharmacists to see enough patients in order to financially justify their position through reimbursement only unless the rate changes.

The goal of improved patient health continues to lead to the development of pharmacist-run services; however, the lack of financial sustainability may threaten this growth. Further advocacy for pharmacist provider status at a federal level needs to continue, not only to ensure the sustainability of pharmacist-run services but, more importantly, to continue to improve 
patient outcomes, decrease ED use, and reduce hospitalization or readmission.

\section{Limitations}

This study has several limitations. First, only two 0.5 FTE pharmacists provided services during the pilot program at any one time, accounting for a small percentage of the overall number of completed visits within each clinic setting, so generalizability of results may be limited. Second, the goal of the pilot program changed during the course of the program from targeting patients qualifying as polypharmacy to chronic disease state management. It is unclear how this may have affected the results. Third, we did not evaluate patient outcomes of this program.

Finally, the results of this study may not be generalizable to a wider population, since it was conducted in a rural setting in Oregon. A 2017 survey of Oregonians found that 94\% of the population of Oregon had insurance: $52 \%$ commercial group or private insurance, 26\% Oregon Medicaid, 15\% Medicare, and $6 \%$ uninsured. ${ }^{13}$ Similarly, Santiam's Aumsville Medical Clinic reported $98 \%$ of its patient population was covered by medical insurance with 45\% commercial, 27\% Medicare, 26\% Oregon Medicaid, and 2\% uninsured. While minute differences exist in the payer mix, we believe that this study approximates what would be found throughout the state of Oregon and is generalizable.

\section{Conclusions}

Even in the best case scenario, with pharmacists solely focused on direct patient care, pharmacist-run services within these 2 rural health primary care clinics was not financially justifiable via direct billing of third-party payers alone. The lack of federal credentialing, recognition of pharmacists as providers, and reimbursement is inadequate for program expansion and sustainability without relying on additional revenue streams or benefits from improved patient outcomes. Currently, federal insurance significantly contributes to this lack of funding.

\section{Authors}

NATHAN D. HOOVER, PharmD, Pacific University, Forest Grove, Oregon, and Santiam Hospital, Stayton, Oregon. R. BRIGG TURNER, PharmD, BCPS-AQ ID, Pacific University, Forest Grove, Oregon. JAIME SAMPSON; TIFFANIE PYE, PharmD, BCPS; and TANIE HOTAN, MD, Santiam Hospital, Stayton, Oregon.

AUTHOR CORRESPONDENCE: Nathan D. Hoover, PharmD, Pacific University, 222 SE 8th Ave., Hillsboro, OR 97123.

Tel.: 503.352.2609; E-mail: Nhoover@pacificu.edu.

\section{DISCLOSURES}

No outside funding provided support for this research; however, funding from Willamette Valley Community Health was given in the form of a grant to partially fund the comprehensive medication management pilot program. Pharmacists were paid from this grant, while Sublimity Pharmacy compensated pharmacists in the form of benefits. The authors have nothing to disclose

This work was presented in part as a poster at the ASHP Midyear Clinical Meeting; December 4, 2018; Anaheim, CA, and as a peer-reviewed podium presentation at the Northwestern States Residency Conference; May 4, 2019; Portland, OR

\section{ACKNOWLEDGMENTS}

The authors thank the administration, providers, and staff of Santiam Hospital and clinics for allowing this comprehensive medication management program to begin within its facilities.

\section{REFERENCES}

1. Patel E. Ambulatory care pharmacy resident Q\&A. Pharmacy Times. December 22, 2015. Available at: https://www.pharmacytimes.com/contributor/ekta-patel/2015/12/ambulatory-care-pharmacy-resident-qa. Accessed November 26, 2019

2. Bingham JT, Mallette JJ. Federal Bureau of Prisons clinical pharmacy program improves patient Alc. J Am Pharm Assoc (2003). 2016;56(2):173-77.

3. Renaudin P, Boyer L, Esteve M, Bertault-Peres P, Auquier P, Honore S. Do pharmacist-led medications reviews in hospitals help reduce hospital readmissions? A systematic review and meta-analysis. Br J Clin Pharmacol. 2016;82(6):1660-73

4. American Pharmacists Association. Provider status: what pharmacists need to know now. September 2013. Available at: https://www.pharmacist com/provider-status-what-pharmacists-need-know-now. Accessed November 26, 2019

5. Oregon State Legislature. House Bill 2028. Section 1-14 (2015). Available at: https://olis.leg.state.or.us/liz/2019R1/Downloads/MeasureDocument/ HB2028. Accessed November 26, 2019.

6. Bonner L. Pharmacist provider status now law in Oregon. Pharmacy Today. June 18, 2015. Available at: https://www.pharmacist.com/article/ pharmacist-provider-status-now-law-oregon. Accessed November 26, 2019.

7. Council for Affordable Quality Healthcare. About CAQH. 2019. Available at: https://www.caqh.org/about/about-caqh. Accessed December 9, 2019.

8. American Society of Health-System Pharmacists. Pharmacist billing for ambulatory pharmacy patient care services in a physician-based clinic and other non-hospital-based environments-FAQ. May 2014. Available at: https://www.ashp.org/-/media/assets/ambulatory-care-practitioner/docs/.

9. Kliethermes MA. Understanding health care billing basics. Pharmacy Today. 2017;23(7):57-68. Available at: https://www.pharmacytoday.org/ article/S1042-0991(17)30973-8/fulltext. Accessed November 26, 2019.

10. Sachdev GP. Ambulatory care pharmacist services: the value proposition Am J Health Syst Pharm. 2018;75(21):1688-89.

11. Carrington A, Pokallus A, Ulrich I, et al. Essential factors demonstrating readiness of primary care practices for clinical pharmacy services. Am J Health Syst Pharm. 2018;75(21):1708-13.

12. Fixen DR, Linnebur SA, Parnes BL, et al. Development and economic evaluation of a pharmacist-provided chronic care management service in an ambulatory care geriatrics clinic. Am J Health Syst Pharm. 2018;75(22):1805-11.

13. Oregon.gov. Oregon Health Insurance Survey. Uninsurance fact sheet 2017. Oregon Health Authority. Available at: https://www.oregon.gov/oha/ HPA/ANALYTICS/InsuranceData/2017-OHIS-Uninsurance.pdf. Accessed November 26, 2019. 